\title{
Latent profile analysis of COVID-19 fear, depression, anxiety, stress, mindfulness, and resilience
}

\author{
İlhan Yalçın ${ }^{1,2}$ (D) Nesime Can ${ }^{1}$ • Öykü Mançe Çalışır ${ }^{1}$. Seher Yalçın ${ }^{3}$ • Burçin Çolak ${ }^{4}$ \\ Accepted: 22 March 2021 / Published online: 31 March 2021 \\ (C) The Author(s), under exclusive licence to Springer Science+Business Media, LLC, part of Springer Nature 2021
}

\begin{abstract}
The purpose of the current study was to identify latent profiles of COVID-19 fear, depression, anxiety, stress, mindfulness, and resilience among university students. A total of 506 university undergraduate and graduate students from various universities were recruited through online platforms in Turkey. Data were collected utilizing self-report scales and were analyzed utilizing latent profile analysis. Results indicated significant relationships among COVID-19 fear, depression, anxiety, stress, resilience, and mindfulness. A three-class solution was adapted to fit the current data. Findings revealed that $46 \%$ of the participants were classified into the high COVID-19 fear and medium psychological symptoms profile. Also, 38\% of the participants were identified as low psychological symptoms and high mindfulness and resilience. Additionally, $16 \%$ of the participants were classified as high COVID-19 fear, psychological symptoms and low mindfulness and resilience. Female gender was positively associated with COVID-19 fear, depression, anxiety, and stress. Life satisfaction and social support were positively associated with the mindfulness and resilience, and were negatively related to COVID-19 fear, depression, anxiety, and stress.
\end{abstract}

Keywords COVID-19 fear $\cdot$ Depression $\cdot$ Anxiety $\cdot$ Stress $\cdot$ Resilience $\cdot$ Mindfulness Latent profile analysis

\section{Introduction}

During December 2019 in Wuhan, China, the COVID-19 epidemic began to occur, and has now become a global problem

İlhan Yalçın

yalcini@ankara.edu.tr

Nesime Can

nesime.can@ankara.edu.tr

Öykü Mançe Çalışır

ocalisir@education.ankara.edu.tr

Seher Yalçın

yalcins@ankara.edu.tr

Burçin Çolak

bcolak@ankara.edu.tr

1 Department of Guidance and Psychological Counseling, Ankara University, Ankara, Turkey

2 Faculty of Educational Sciences, Ankara University, Cebeci Campus, 06590 Ankara, Turkey

3 Department of Measurement and Evaluation in Education, Ankara University, Ankara, Turkey

4 Department of Psychiatry, Ankara University, Ankara, Turkey and has been declared as a pandemic by the World Health Organization (WHO). Because of the COVID-19 outbreak in Turkey, all schools and universities were closed, and students participated in distance education from March to June in 2020, similar to many other countries. Although closing educational institutions lowered the pandemic speed, the daily routine of students was interrupted as well as their psychosocial needs. In this study, the researchers aimed to explore COVID-19 fear and its relationships with depression, anxiety, stress, mindfulness, and resilience among undergraduate and graduate students.

Epidemics affect various segments of society in different ways, and may influence how some people show signs of depression, anxiety, and stress (Balsamo \& Carlucci, 2020; Carlucci et al., 2020). The psychological state of people during the SARS-CoV outbreak (2002-2003) was called a "mental health catastrophe" (Mak et al., 2009). Mental health problems occurring during the COVID-19 have been identified by professionals as a "parallel pandemic" (Mucci et al., 2020). They include post-traumatic stress disorder, emotional disturbance, sleep disorders, depressive syndromes and related suicides. Variables that make people psychologically vulnerable have been noted in previous epidemics, and found in related literature. Taylor (2019) indicated that negative emotionality, a tendency to become anxious, the inability 
to tolerate uncertainty, and perceived vulnerability to disease, and feelings of helplessness towards illness are some of these variables. People who were directly or indirectly affected by the outbreak showed the following symptoms: fear of illness and death, fear of being separated from their loved ones due to quarantine, fear of losing their loved ones due to virus, feeling helpless due to social isolation, feeling distressed, loneliness and depressive symptoms (Hall et al., 2008; International Federation of Red Cross and Red Crescent Societies (IFRC), 2020). The WHO emphasized that anxiety, anger, stress or agitation may appear, and withdrawn behaviors might emerge because of self-isolation and social distancing (World Health Organization, 2020). At the beginning of the COVID-19 pandemic, Mazza et al. (2020) found that female gender, negative affect, and detachment were positively related to depression, anxiety, and stress. Similarly, Balsamo and Carlucci (2020) have reported that females, younger people, and students were at high risk regarding experiencing depressive symptoms during COVID-19 outbreak.

At the beginning of the SARS-CoV outbreak, frequently reported psychiatric symptoms were depression, anxiety, panic attacks, psychomotor excitement, psychotic symptoms, delirium, and even suicidality (Xiang et al., 2020; Maunder et al., 2003). Additionally, an increase in the level of stress, anxiety, and depression were also found in students and in participants with physical symptoms or chronic conditions (Wang et al., 2020). In a COVID-19 study that surveyed a total of 7000 participants in China, researchers found that participants under 35 years of age were more vulnerable to anxiety and depressive symptoms compared to other age groups (Huang \& Zhao, 2020). These findings were paralleled with the findings in the SARS-CoV outbreak in Taiwan $\mathrm{Su}$ et al., 2007). Some studies also stated that in terms of general mental health during COVID-19 outbreak, the vulnerable age group was between 21 and 40 years old (Ahmed et al., 2020; Moghanibashi-Mansourieh, 2020). Therefore, university students can be considered as one of the vulnerable groups as many students may be psychologically affected by COVID19 epidemic. Reasons for increasing the anxiety among university students may be distancing from other people (Cao et al., 2020) (especially from the ones they care about), concerns about employment difficulties in the future (Wang et al., 2020), and the effects the virus may have on their education (Cornine, 2020). During the COVID-19 outbreak, one of the first studies conducted with the sample group of university students asserted that anxiety levels of university students were higher than the general population (Wang \& Zhao, 2020).

Fear is one of the basic human emotions and plays a critical role in the evolutionary emotional continuity of humanity. Fear may be destructive or harmful on mental health when it rises above a certain level, similar to anxiety or stress. In the existing literature, researchers identified some characteristics of fear related to the coronavirus. The Coronavirus Stress Scale includes items related to domains including danger and contamination, fears about economic consequences; coronavirus-related xenophobia; compulsive checking and reassurance seeking; traumatic stress symptoms (Taylor et al., 2020). In a study by Schimmenti et al. (2020), four domains of fear were indicated including fear for the body, fear for significant others, fear of not knowing, and fear of inaction. Mertens et al. (2020) found that individual differences related to anxiety, accessing information about the coronavirus outbreak through use of media and social media), and risks for loved ones were predictors of increased fear of COVID-19. Also, researchers found associations between COVID-19 fear and anxiety, depression, and stress (Bakioğlu et al., 2020; Harper et al., 2020).

Many researchers have emphasized the importance of resilience in coping with the COVID-19 pandemic (Chen et al., 2020; Kuipers, 2020; Polizzi et al., 2020; Vinkers et al., 2020; Wang et al., 2020), since the pandemic may cause stressful and difficult life situations. Polizzi et al. (2020) reviewed how people responded to the current major crises compared to disasters experienced in previous years and stated that previously used coping strategies such as compulsory isolation, social distance, fear of catching a deadly disease, and hopelessness may be used in current challenges during the COVID-19 pandemic. It is noteworthy that the most recommended strategies to use included stress management, and enhancing resilience. Considering resilience as a protective factor, it is necessary to continue to examine the association between resilience and COVID-19 fear to provide better support to those who are in need. Similarly, mindfulness should be taken into consideration for decreasing negative effects of COVID-19 pandemic. As literature reviews have suggested, mindfulness practices are effective on coping with stress, anxiety, and depression; therefore, individuals may practice mindfulness to cope with presenting negative symptoms during the global COVID-19 pandemic (Behan, 2020; Khoury et al., 2015; Li et al., 2020). With support for this idea, Behan (2020) reviewed the benefits of meditation and mindfulness practices, and recommended utilizing such tools to help enhance coping skills of individuals in this difficult time.

During difficult times, people might be concerned about their health. During a pandemic, people might be anxious about their health which may decrease their level of well-being. Life satisfaction is considered as one of the essential components of the subjective well-being (SWB). Overall life satisfaction is determined as a cognitive judgement component of SWB (Diener et al., 1985). Additionally, one of the factors associated with well-being is physical health (Huelsnitz et al., 2018). Also, numerous studies have investigated the associations between social relationships, treatment of diseases, and well-being (Cohen et al., 2000; Ferreira \& Sherman, 2007). Social support is beneficial for individuals both through its 
direct effect and buffering effects which means that it protects people from stressful life events (Cohen \& Wills, 1985). Forshaw (2002) suggested that social support might be beneficial for the reduction of the damaging effects of stress. Perceived support from social contacts might have positive effects on the physical health of people (Sarafino \& Smith, 2011). For these reasons, life satisfaction and perceived social support of participants were examined in order to better understand their relationships with COVID-19 fear, depression, anxiety, stress, mindfulness, and resilience.

In the current study, the researchers aimed to examine relationships among COVID-19 fear, depression, anxiety, stress, resilience, and mindfulness using latent profile analysis. Although there are numerous studies on COVID-19 fear and its various dimensions, there has been a paucity of research regarding the antecedents of COVID-19 fear among university students. When examining the participants as a homogeneous group, studies on COVID-19 fear and associated variables might have some limitations in terms of revealing detailed information. In this study, researchers attempted to identify latent classes through latent profile analysis, based on the all measurements from individuals. By using the classification of the participants, latent profiles in terms of COVID-19 fear, depression, anxiety, stress, mindfulness, and resilience were compared. Additionally, latent profiles were compared in terms of some demographic characteristics and continuous variables such as life satisfaction and perceived social support. Life satisfaction was not included in the latent profile analysis, because it represents cognitive judgement of a person's life as a whole, whereas majority of the variables included in the latent profile analysis represent affective characteristics. Thus, it was decided to separately examine the contributions of life satisfaction and social support to the latent profiles and their relationships with latent profiles.

\section{Method}

\section{Participants}

A sample of 506 undergraduate and graduate students from various universities in Turkey participated in this study between April and May 2020. The purposeful sampling method, specifically criterion and snowball sampling methods, were used to recruit the participants (Patton, 2001). Upon obtaining institutional review board approval, an online survey package was created with an online link which was shared with students and also professionals for the purpose of dissemination of the link with potential participants. In terms of participant characteristics, the sample consisted of $78.7 \%(n=398)$ female and $21.3 \%(n=108)$ male. The mean age of the participants was 21.69 with a standard deviation of 3.08 , and ages ranged between 18 and 39. Among the 506 participants, $95.6 \%(n=484)$ were undergraduate students, and $4.4 \%$ $(n=22)$ were graduate students.

\section{Measures}

\section{Fear of COVID-19 Scale (FCV-19S)}

The seven-item and one-dimensional Fear of COVID-19 Scale (FCV-19S) was developed to measure the level of fear that occurs in individuals due to COVID-19 (Ahorsu et al., 2020). Adaptation of the scale into Turkish was completed by Haktanir et al. (2020). The reliability coefficient was reported as 0.82 . In the present study, confirmatory factor analysis indicated that the one-factor model demonstrated an acceptable fit to the data: $\chi^{2} / d f=5.31$, RMSEA $=0.15, \mathrm{CFI}=0.96$, $\mathrm{TLI}=0.94$. In this study, a Cronbach alpha coefficient of the scale was 0.86 .

\section{Depression, Anxiety, Stress Scales (DASS)}

The 4-point Likert type Depression, Anxiety, Stress Scale (DASS) was developed to measure levels of depression, anxiety, and stress among individuals (Lovibond \& Lovibond, 1995), and consists of 21 items and 3 sub-dimensions. Sarıçam (2018) developed the Turkish version of the form and conducted validity and reliability study. In the clinical sample, Cronbach's alpha coefficient was 0.87 for the depression subscale, 0.85 for the anxiety subscale, and 0.81 for the stress subscale. In the normal sample, test-retest correlation coefficients were reported as 0.68 for the depression subscale, 0.66 for the anxiety subscale, and .61 for the stress subscale. In the present study, confirmatory factor analysis indicated that the three-factor model demonstrated a good fit to the data: $\chi^{2} /$ $d f=3.56$, RMSEA $=0.07$, CFI $=0.94$, TLI $=0.93$ (Tabachnick \& Fidell, 2007). Additionally, the Cronbach's alpha coefficient of the depression, anxiety, and stress dimensions was $0.86,0.75$, and 0.80 , respectively.

\section{Brief Resilience Scale (BRS)}

The Brief Resilience Scale (BRS), developed by Smith et al. (2008) consisting of 6 items, was designed to measure the ability of individuals to overcome difficult situations. On the Turkish form of this scale which uses a Likert type five-point scoring, tests of validity and reliability were conducted by Haktanir et al. (2016). The test-retest reliability coefficients of the BRS were reported as good between 0.80 and 0.91 . In the present study, confirmatory factor analysis indicated that the one-factor model demonstrated a good fit to the data: $\chi^{2} /$ $d f=2.46$, RMSEA $=0.12$, CFI $=0.98$, TLI $=0.97$ (Tabachnick \& Fidell, 2007). Cronbach's alpha coefficient of the scale was found to be 0.85 for this study. 


\section{Mindful Attention Awareness Scale (MAAS)}

The Mindful Attention Awareness Scale (MAAS) was developed to measure the tendency of individuals to be aware of their immediate experiences in daily life (Brown \& Ryan, 2003). A 15 -item scale, is a one-factor structure. The adaptation study of the scale into Turkish was completed by Özyeșil et al. (2011), and the internal consistency coefficient was calculated as 0.80 , while the test-retest correlation was 0.86 . In the present study, confirmatory factor analysis indicated that the one-factor model demonstrated an acceptable fit to the data: $\chi^{2} / d f=5.28$, RMSEA $=0.095$, CFI $=0.93$, TLI $=0.92$ (Tabachnick \& Fidell, 2007). In this study, Cronbach's alpha coefficient of the scale was 0.86 .

\section{Satisfaction with Life Scale (SLS)}

The Satisfaction with Life Scale (SLS) was developed by Diener et al. (1985), and adapted to Turkish by Dağlı and Baysal (2016) to measure general life satisfaction, which is suitable for all ages, from adolescents to adults. The scale consists of five items regarding life satisfaction. The testretest reliability coefficient of the scale was 0.85 . In the present study, confirmatory factor analysis indicated that the onefactor model demonstrated a good fit to the data: $\chi^{2} / d f=0.75$, RMSEA $=0.07, \mathrm{CFI}=0.99, \mathrm{TLI}=0.99$. In this study, a Cronbach's alpha coefficient of the scale was 0.86 .

\section{Multidimensional Scale of Perceived Social Support (MSPSS)}

The Multidimensional Scale of Perceived Social Support (MSPSS), including three sub-dimensions (i. e. family, friend, and a significant other), and consisting of 12 items in total, was developed to evaluate the sufficiency of social support that individuals receive from three different sources (Zimet et al., 1990). The 7-point Likert type scale was adapted, validated, and formatted into Turkish language by Eker et al. (2001). The internal consistency values were reported to be at a good level between 0.80 and 0.95 . In the present study, confirmatory factor analysis indicated that the three-factor model demonstrated a good fit to the data: $\chi^{2} / d f=1.60$, RMSEA $=0.059$, CFI $=0.99$, TLI $=0.99$ (Tabachnick \& Fidell, 2007). In this study, the Cronbach's alpha coefficient was .89, and Cronbach's alpha coefficients of the dimensions identified as family, friend, and a significant other were 0.90 , 0.93 and 0.97 , respectively.

\section{Data Analysis}

Prior to data analysis, test assumptions and descriptive statistics were examined for the variables. In this context, the data were first examined in terms of missing data and extreme values. When all the variables in the study were examined, there was no missing data in the data set. In the preliminary analysis, 24 individuals with single and multivariate extreme values were excluded from the analysis, and 506 persons remained in the latest data set. Data were then reviewed for normality of distribution, multicollinearity, multivariate normality, and linearity. It was determined that all the assumptions were met. Second, confirmatory factor analysis was conducted in Mplus 8.4 (Muthén \& Muthén, 1998-2017) to reveal the structure of the measuring tools used. In the evaluation of the results, with large sample sizes, the Chi-square statistic was often statistically significant. In addition, $\chi^{2} / d f$ value was often used as an evaluation. Three other indices of fit to evaluate the adequacy of all models used in this study were (a) the comparative fit index (CFI), (b) the Tucker-Lewis index (TLI), and (c) the root mean square error of approximation (RMSEA). Fit of the models was considered as acceptable when the CFI and TLI values were above 0.90, the RMSEA values were below 0.08 and $\chi^{2} / d f$ values were below 5 (Kline, 2011; Tabachnick \& Fidell, 2007).

Latent profile analysis on the COVID-19 fear, depression, anxiety, stress, mindfulness, and resilience was conducted. Latent profile analysis is a statistical procedure in which continuous latent indicators are utilized while performing latent class analysis (Muthén \& Muthén, 1998-2017). Data analysis was completed in four steps. The first step of the latent profile analysis is to determine the number of latent profiles among study group. In order to determine the number of latent profiles, Bayesian information criterion (BIC), Lo-Mendell-Rubin likelihood ratio test (LMR-LRT), the entropy value, and posterior probabilities were used. Accordingly, smaller values of information criterion indicate a better model fit. Also, an insignificant $(p>0.05)$ LMR-LR test value indicates that adding more profiles into the model does not improve the model. Additionally, a value closer to 1.0 for the entropy values indicates a better decision on the number of profiles to include (Wang \& Wang, 2020). After determining the optimal number of the latent profiles and profile membership probabilities of the participants, various characteristics of the latent profiles were investigated and the latent profiles were labeled according to common characteristics of members. During the second step in regard to study variables, differences across latent profiles were examined using the one-way analysis of variance (ANOVA). The third step included regression analysis in which COVID19 fear, depression, anxiety, stress, mindfulness, and resilience were regressed on posterior profile membership probabilities. In the last step, variables of gender, age, life satisfaction, and social support were considered to be related to latent profiles, and were included in the regression analysis with posterior profile membership probabilities. The latent profile analysis was conducted with Mplus 8.4 (Muthén \& Muthén, 1998-2017), and SPSS 
21.0 software was used for one-way ANOVA and regression analysis.

\section{Results}

Correlations, means, and standard deviations for study variables are shown in Table 1. As presented in Table 1, significant associations were found among all variables.

\section{Latent Profile Analysis}

Latent profile analysis began with one-class solution and then the number of the profiles were increased. Table 2 indicates the one- to five-profile models used to determine the optimal profile number. The three-class model was determined as the best model to fit the data. As presented in Table 2, BIC values were close to each other for the three- and four-class model. The LMR-LR test was not significant for the four-class model which indicated that the $k$ - 1 class number is more parsimonious and preferable. The entropy value was 0.79 for the threeclass model which indicates a higher value. It was concluded that within the study group there were three latent classes in terms of COVID-19 fear, depression, anxiety, stress, mindfulness, and resilience.

In the next step of the latent profile analysis, general patterns of the profiles were presented. For this purpose, mean and standard deviations of the study variables were investigated across the latent profiles. As presented in Fig. 1, latent profiles had different characteristics regarding study variables. For instance, Profile 1 contained those students with high COVID-19 fear and medium depression, anxiety, stress, mindfulness, and resilience, and consequently was named "High COVID-19 fear and medium psychological symptoms". Latent Profile 1 included 233 students (46\% of the participants). Those students with low COVID-19 fear, depression, anxiety, stress, and high in mindfulness and resilience were classified into Profile 2, and was labeled "Low psychological symptoms and high mindfulness and resilience". Latent Profile 2 consisted of 191 students (38\% of the participants). Profile 3 included students who had high COVID-19 fear, depression, anxiety, stress, and low mindfulness and resilience, and was labeled as "High COVID-19 fear, psychological symptoms and low mindfulness and resilience". Latent Profile 3 consisted of 82 students (16\% of the participants). Figure 1 indicates the graphical illustration of the latent profiles using standardized z-scores.

After determining the optimal number of the latent profiles, a one-way ANOVA was utilized to compare the profiles regarding COVID-19 fear, depression, anxiety, stress, mindfulness, and resilience. As shown in Table 3, there were significant $F$ values indicating significant differences in the study variables across latent profiles. Post hoc comparison using the Tukey HSD test indicated significant differences in COVID-19 fear, depression, anxiety, stress, mindfulness, and resilience across all the three profiles. Specifically, those classified into Profile 3 had scored higher on COVID-19 fear, depression, anxiety, and stress than Profile 1 and 2. Also, individuals belonging to Profile 3 reported lower mindfulness and resilience.

In order to investigate the relationships between latent profile membership and study variables, COVID-19 fear, depression, anxiety, stress, mindfulness, and resilience were regressed on posterior profile membership probabilities. As seen in Table 4, results revealed that depression and stress were positively associated, and anxiety, mindfulness, and resilience were negatively associated with Profile 1. Additionally, COVID-19 fear, depression, anxiety, and stress were negatively associated, and mindfulness and resilience were positively associated with Profile 2 . Also, COVID-19 fear, depression, and anxiety were positively associated, and resilience was negatively associated with Profile 3.

In the last step of the analysis, some related variables such as gender, age, life satisfaction, and social support were regressed on posterior profile membership probabilities. When posterior profile membership probabilities for Profile 1 was predicted, a significant regression equation was found $F(4,501)=11.190, p<0.001$, with an $R^{2}$ of 0.08 . It was found that female gender was positively associated ( $\beta=0.120, p<0.01)$, and life satisfaction was negatively associated $(\beta=-0.260, p<0.001)$ with Profile 1 . When membership probabilities for Profile 2 was predicted, a significant regression equation was found $F(4,501)=25.782, p<0.001$, with an $R^{2}$ of 0.17 . It was found that female gender was
Table 1 Correlations, Means (M), and Standard Deviations (SD) for the Study Variables

\begin{tabular}{lllllllll}
\hline Variable & 1 & 2 & 3 & 4 & 5 & 6 & $\mathrm{M}$ & $\mathrm{SD}$ \\
\hline 1. COVID-19 fear & - & & & & & 16.88 & 5.01 \\
2.Depression & $0.241^{* *}$ & - & & & & 6.10 & 4.19 \\
3.Anxiety & $0.369^{* *}$ & $0.494^{* *}$ & - & & & 2.72 & 2.72 \\
4.Stress & $0.357^{* *}$ & $0.662^{* *}$ & $0.604^{* *}$ & - & & 6.12 & 3.55 \\
5. Resilience & $-0.306^{* *}$ & $-0.358^{* *}$ & $-0.338^{* *}$ & $-0.394^{* *}$ & - & 18.13 & 4.73 \\
6.Mindfulness & $-0.124^{* *}$ & $-0.399^{* *}$ & $-0.401^{* *}$ & $-0.425^{* *}$ & $0.328^{* *}$ & - & 57.69 & 11.91 \\
\hline
\end{tabular}

Note: $* * p<0.01$ 
Table 2 Model Fit Statistics for Determining the Optimal Number of Classes

\begin{tabular}{lllll}
\hline Model & BIC & LMR LRT $(\mathrm{p})$ & Class assignment probability (class size) & Entropy \\
\hline 1 class & $18,140.65$ & - & - & 0.79 \\
2 classes & $17,518.68$ & $650.62(0.001)$ & $0.95(59 \%) / 0.93(41 \%)$ & $\mathbf{0 . 7 9}$ \\
3 classes & $\mathbf{1 7 , 3 5 6 . 0 7}$ & $\mathbf{2 0 1 . 5 7 ( \mathbf { 0 . 0 0 1 } )}$ & $\mathbf{0 . 8 9}(\mathbf{4 6 \% )} / \mathbf{0 . 9 1 ( 3 8 \% ) / 0 . 9 0 ( 1 6 \% )}$ & 0.76 \\
4 classes & $17,355.18$ & $43.48(0.23)$ & $0.92(38 \%) / 0.69(12 \%) / 0.85(36 \%) / 0.93(14 \%)$ & 0.79 \\
5 classes & $17,330.23$ & $66.99(0.43)$ & $0.91(33 \%) / 0.90(9 \%) / 0.80(16 \%) / 0.85(11 \%) / 0.84(31 \%)$ & \\
\hline
\end{tabular}

BIC Bayesian Information Criteria, LMR LRT Lo-Mendell-Rubin adjusted likelihood ratio test. Bold type indicates the selected best fit model

negatively associated $(\beta=-0.225, p<0.001)$; life satisfaction $(\beta=0.298, p<0.001)$ and social support $(\beta=0.112, p<0.05)$ were positively associated with Profile 2 . When membership probabilities for Profile 3 was predicted, a significant regression equation was found $F(4,501)=5.30, \mathrm{p}<0.001$, with an $R^{2}$ of 0.04 . It was found that female gender was positively associated $(\beta=0.137, p<0.01)$, and social support was negatively associated $(\beta=-0.128, p<0.01)$ with Profile 3 . Age of the participants was not found to be associated with any of the latent classes.

\section{Discussion}

Based on the existing literature related to COVID-19 fear and psychological variables, the current study examined the latent model of the COVID-19 fear and its association with depression, anxiety, stress, mindfulness, and resilience. Analysis of model tests revealed that a three-class solution best fit the data. The research sample was classified into three conceptually meaningful latent profiles based on indicator variables. The findings indicated that there were different reactions to the COVID-19 pandemic in terms of fear and psychological symptoms. Also, latent profiles had specific characteristics in terms of study variables.

Specifically, members of Profile 1 had a higher level of COVID-19 fear, whereas they had a medium level of depression, anxiety, stress, mindfulness, and resilience. Members of
Profile 2 had a lower level of COVID-19 fear, depression, anxiety, and stress, while they had higher levels in mindfulness and resilience. The researchers concluded that members of Profile 2 were better able to protect their mental health during the coronavirus pandemic. Lastly, members of Profile 3 had higher levels of COVID-19 fear, depression, anxiety, and stress, whereas they had lower levels of mindfulness and resilience. It may be concluded that individuals who have similar characteristics to members of the Profile 3 should be taken into consideration when providing university counseling services.

In the current study, COVID-19 fear, depression, anxiety, and stress were found to co-exist in individuals, especially in the members of Profile 2 and Profile 3. All these variables together are high in Profile 3 , and all are together low in Profile 2. Fear of infectious diseases may be more common within societies during pandemics. Accordingly, COVID-19 fear may share a comorbidity with perceived vulnerability to disease. For example, in a study by Duncan et al. (2009), which included undergraduate students in the sample, perceived infectability including beliefs about vulnerability to future health problems, and is specific to infectious diseases had significant and positive correlations with hypochondria and health anxiety. Additionally, Taylor and Asmundson (2004) stated that increased health anxiety may also lead to depressive disorders. Thus, it might be stated that fear of infectious diseases increases the likelihood of some
Fig. 1 Line graph comparing profiles on study variables in zscore format

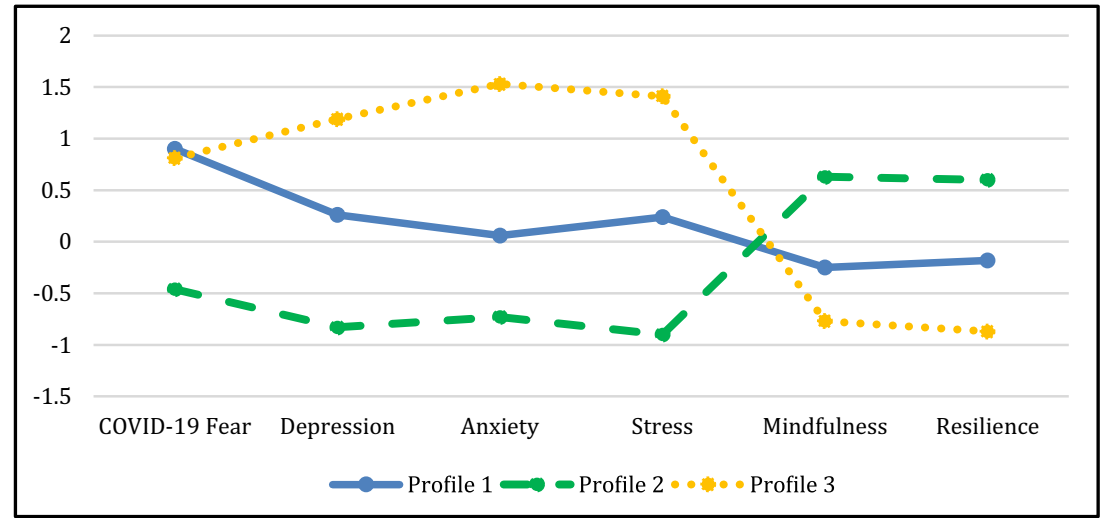


Table 3 Analysis of Variance across Latent Profiles

\begin{tabular}{|c|c|c|c|c|c|}
\hline Variables & $\begin{array}{l}\text { Profile } 1 \\
\text { (High COVID-19 } \\
\text { fear and medium } \\
\text { psychological } \\
\text { symptoms) } \\
(n=233) \mathrm{M}(\mathrm{SD})\end{array}$ & $\begin{array}{l}\text { Profile } 2 \\
\text { (Low psychological } \\
\text { symptoms and high } \\
\text { mindfulness, } \\
\text { resilience) } \\
(n=191) \mathrm{M}(\mathrm{SD})\end{array}$ & $\begin{array}{l}\text { Profile } 3 \\
\text { (High COVID-19 fear, } \\
\text { psychological symptoms } \\
\text { and low mindfulness, re- } \\
\text { silience) } \\
(n=82) \mathrm{M}(\mathrm{SD})\end{array}$ & $\begin{array}{l}F(2, \\
503)\end{array}$ & $p$ \\
\hline $\begin{array}{l}\text { COVID-19 } \\
\text { fear }\end{array}$ & $17.33(4.51)$ & $14.58(4.33)$ & $20.96(4.92)$ & 59.60 & $<0.001$ \\
\hline Depression & $7.19(3.21)$ & $2.63(2.11)$ & $11.07(3.59)$ & 270.13 & $<0.001$ \\
\hline Anxiety & 2.88 (1.97) & $0.74(1.11)$ & $6.89(2.24)$ & 354.86 & $<0.001$ \\
\hline Stress & $6.99(2.12)$ & $2.91(1.89)$ & $11.13(2.36)$ & 486.62 & $<0.001$ \\
\hline Mindfulness & $54.76(10.44)$ & $65.21(9.78)$ & 48.48 (10.19) & 95.87 & $<0.001$ \\
\hline Resilience & $17.27(4.35)$ & $20.95(3.80)$ & $14.02(3.65)$ & 94.18 & $<0.001$ \\
\hline
\end{tabular}

psychological symptoms such as depression, anxiety, and stress. A study conducted by Bitan et al. (2020), found fear of COVID-19 was significantly correlated with depression, anxiety, and stress. Similarly, Huang and Zhao (2020) found that participants under 35 years of age had greater COVID-19 related generalized anxiety disorder than individuals ages 35 and older. Specifically, this finding was important, since the current study included participants who were both undergraduate and graduate students. Additionally, Satıc1 et al. (2020) reported that fear of COVID-19 was significantly associated with depression, anxiety, and stress. Taylor and Asmundson (2004) posited that fear related to disease might occur in two different forms: (a) a person might be fearful because of currently having the disease; and (b) a person might fear contracting the disease in the future. Cognitive distortions might lead to these excessive fears about disease. A study by Rief et al. (1998), noted intolerance of bodily complaints were significantly associated with hypochondriasis. Individuals with higher fear of contracting an infectious disease might misinterpret the bodily sensations. These misinterpretations may lead an individual into a depressive, anxious, and stressed mood. Also, Taylor (2019) indicated that individuals may face some sources of stress during pandemics. The stressors might be associated with psychological, social, or health issues, such as interrupting daily life habits, social distancing from loved ones, and staying away from school environments, etc. These and other negative effects of pandemics include individual uncertainties about the future. Such uncertainties might create depression, anxiety, and stress among individuals.

In all three latent profiles, levels of both mindfulness and resilience are similar. Mindfulness and resilience were both found to be high or low concurrently, and have negative associations with COVID-19 fear, depression, anxiety, and stress. Killgore et al. (2020) and Liu et al. (2020) reported similar results stating that individuals with higher resilience scores reported lower levels of depression. Many researchers suggested resilience may be considered a protective factor among university students in coping with COVID-19 related psychological problems (Chen et al., 2020; Kuipers, 2020; Polizzi et al., 2020; Vinkers et al., 2020; Wang et al., 2020). Additionally,

Table 4 Results of Regression Analysis of Posterior Class Membership Probabilities on Study Variables

\begin{tabular}{|c|c|c|c|c|c|c|c|c|c|}
\hline & \multicolumn{3}{|c|}{$\begin{array}{l}\text { Latent Profile } 1 \\
(n=233)\end{array}$} & \multicolumn{3}{|c|}{$\begin{array}{l}\text { Latent Profile } 2 \\
(n=191)\end{array}$} & \multicolumn{3}{|c|}{$\begin{array}{l}\text { Latent Profile } 3 \\
(n=82)\end{array}$} \\
\hline & $\beta$ & $t$ & $p$ & $\beta$ & $t$ & $p$ & $\beta$ & $t$ & $p$ \\
\hline COVID-19 Fear & 0.037 & 0.788 & 0.431 & -0.094 & -3.640 & $<0.001$ & 0.074 & 2.458 & $<0.05$ \\
\hline Depression & 0.139 & 2.432 & $<0.05$ & -0.240 & -7.587 & $<0.001$ & 0.134 & 3.609 & $<0.001$ \\
\hline Anxiety & -0.239 & -4.348 & $<0.001$ & -0.137 & -4.477 & $<0.001$ & 0.473 & 13.225 & $<0.001$ \\
\hline Stress & 0.165 & 2.608 & $<0.01$ & -0.360 & -10.264 & $<0.001$ & 0.254 & 6.185 & 0.732 \\
\hline Mindfulness & -0.190 & -3.937 & $<0.001$ & 0.168 & 6.297 & $<0.001$ & 0.022 & 0.690 & 0.491 \\
\hline \multirow[t]{2}{*}{ Resilience } & -0.108 & -2.273 & $<0.05$ & 0.154 & 5.852 & $<0.001$ & -0.062 & -2.023 & $<0.05$ \\
\hline & \multicolumn{3}{|c|}{$R^{2}=0.14, F(6,499)=13.397, p<0.001$} & \multicolumn{3}{|c|}{$R^{2}=0.74, F(6,499)=230.211, p<0.001$} & \multicolumn{3}{|c|}{$R^{2}=0.64, F(6,499)=145.783, p<0.001$} \\
\hline
\end{tabular}


resilience practices may provide a multidimensional support mechanism for mental health of students by reducing their level of depression, anxiety, and stress while enhancing their well-being. Based on the results of the current study, it is recommended clinicians continue using resilience resources in their work with university students. Other researchers found mindfulness effective on reducing levels of stress, anxiety, and depression (Khoury et al., 2015; Li et al., 2020). Based on the findings of this study, clinicians may also want to include teaching mindfulness and utilization of mindfulness related practices when working with university students coping with COVID-19 fear, depression, anxiety, and stress as well to enhance students well-being. In an extensive literature review, many researchers suggested utilizing mindfulness to reduce stress, anxiety, depression, and increase wellbeing during COVID-19 pandemic (e.g., Behan, 2020; Di Giuseppe et al., 2020).

Results suggest that female gender is positively associated with Profile 1 and Profile 3, and is negatively related to Profile 2. The common characteristics of both Profile 1 and Profile 3 is that members of both profiles have higher levels of COVID-19 fear, depression, anxiety, and stress, than individuals belonging to Profile 2 . This finding is consistent with other study results that revealed females have higher levels of depression and anxiety (Balsamo \& Carlucci, 2020; Bigalke et al., 2020; Lee \& Crunk, 2020). These results should also be considered when providing counseling services for university students.

Study findings also suggest that life satisfaction is negatively associated with Profile 1, and positively associated with Profile 2. There are significant differences between Profile 1 and Profile 2 in terms of COVID-19 fear, depression, anxiety, stress, mindfulness, and resilience. More specifically, life satisfaction was positively associated with the latent profile, members of which had higher levels in mindfulness and resilience; while life satisfaction was negatively associated with the latent profile, members of which had higher levels in COVID-19 fear, depression, anxiety, and stress. This finding of the current study is in line with the results of studies in the related literature. For example, Satıc1 et al. (2020) found fear of COVID-19 was negatively associated with life satisfaction. Similarly, a study conducted by Trzebiński et al. (2020) reported that life satisfaction was negatively correlated with COVID-19 stress.

In the current study, social support was found to be positively associated with Profile 2 , and negatively associated with Profile 3. Members of Profile 2 had low levels of COVID-19 fear, depression, anxiety, and stress, and had high levels of mindfulness and resilience. The researchers conclude that perceived social support may have an important role in coping with negative sides of the coronavirus pandemic. Individuals may show various psychological symptoms related to the COVID-19 outbreak. Social isolation or social distancing may influence symptoms in individuals such as anxiety, anger, and stress (World Health Organization, 2020). In relationship to public health emergencies, university students may feel anxious, worried or have fear (Mei et al., 2011). Conversely, it is known that individual connections with social network and social support were related to better mental health (Cornwell \& Laumann, 2015). Since Cheung (2015) stated, psychosocial support during Ebola was accepted as lifesaving, one may conclude during difficult times such as pandemics, the support of family, friends, and significant others play a significant role in the mental health of people. Perceived social support may be a protective factor related to COVID-19 fear, depression, anxiety, and stress.

In light of the valuable contributions to the literature, the current study had some limitations. First, the results may not be generalized to the public since participants were university undergraduate and graduate students. Second, self-report measures were used, and social desirability bias may have influenced the results. Third, as a cross-sectional study, cautious consideration is necessary when interpreting the results. Finally, due to the COVID-19 pandemic, study participants were in obligatory home quarantine, and had no other option other than to participate in distance education. Such major life changes may also influence the results.

Future researchers may develop different models to continue to explore various dimensions of COVID-19 fear and associated variables. Future studies might include other protective and risk factors related to coronavirus fear. Conducting qualitative studies on of university students who have experienced the pandemic, may lead to a deeper understanding of the coronavirus fear, and psychological symptoms, as well as functions of well-being variables during pandemics. In several studies on outbreak, young adults were found to be a vulnerable age group (Huang \& Zhao, 2020; Su et al., 2007). Findings in the current study may provide a guide for development of psychological support programs for university students regarding the depression, anxiety, and stress during a pandemic. These programs would be valuable in emphasizing the importance an individual social support system, and the importance of both resilience and mindfulness. Additionally, these findings may assist those working in campus counseling centers with ways to inform students of the importance of these protective factors during the current COVID-19 outbreak.

Funding This research has been supported by Ankara University Scientific Research Projects Coordination Unit. Project Number: 20Y0901009, 2020. 
Data Availability The datasets analyzed during the current study are available from the corresponding author on reasonable request.

\section{Declarations}

Ethical Approval All procedures performed in studies involving human participants were in accordance with the ethical standards of the institutional and/or national research committee and with the 1964 Helsinki declaration and its later amendments or comparable ethical standards.

Informed Consent Informed consent was obtained from all participants for being included in the study.

Conflict of Interest The authors declare that they have no conflict of interest.

\section{References}

Ahmed, M. Z., Ahmed, O., Aibao, Z., Hanbin, S., Siyu, L., \& Ahmad, A. (2020). Epidemic of COVID-19 in China and associated psychological problems. Asian Journal of Psychiatry, 51, 102092. https://doi. org/10.1016/j.ajp.2020.102092.

Ahorsu, D, K., Lin, C, Y., Imani, V., Saffari, M., Griffiths, M, D., \& Pakpour, A, H. (2020). The fear of COVID-19 scale: Development and initial validation. International Journal of Mental Health and Addiction, 1-9. https://doi.org/10.1007/s11469020-00270-8.

Bakioğlu, F., Korkmaz, O., \& Ercan, H. (2020). Fear of COVID-19 and positivity: Mediating role of intolerance of uncertainty, depression, anxiety, and stress. International Journal of Mental Health and Addiction, https://doi.org/10.1007/s11469-020-00331-y.

Balsamo, M., \& Carlucci, L. (2020). Italians on the age of COVID-19: The self-reported depressive symptoms through web-based survey. Frontiers in Psychology, 11, 569276. https://doi.org/10.3389/fpsyg. 2020.569276

Behan, C. (2020). The benefits of meditation and mindfulness practices during times of crisis such as COVID-19. Irish Journal of Psychological Medicine, 37, 1-3. https://doi.org/10.1017/ipm. 2020.38 .

Bigalke, J. A., Greenlund, I. M., \& Carter, J. R. (2020). Sex differences in self-report anxiety and sleep quality during COVID-19 stay-at-home orders. Biology of Sex Differences, 11(1), 1-11. https://doi.org/10. 1186/s13293-020-00333-4.

Bitan, D. T., Grossman-Giron, A., Bloch, Y., Mayer, Y., Shiffman, N., \& Mendlovic, S. (2020). Fear of COVID-19 scale: Psychometric characteristics, reliability and validity in the Israeli population. Psychiatry Research, 289, 113100. https://doi.org/10.1016/j. psychres.2020.113100.

Brown, K. W., \& Ryan, R. M. (2003). The benefits of being present: Mindfulness and its role in psychological well-being. Journal of Personality and Social Psychology, 84, 822-848.

Cao, W., Fang, Z., Hou, G., Han, M., Xu, X., Dong, J., \& Zheng, J. (2020). The psychological impact of the COVID-19 epidemic on college students in China. Psychiatry Research, 287, 112934. https://doi.org/10.1016/j.psychres.2020.112934.

Carlucci, L., D'Ambrosio, I., \& Balsamo, M. (2020). Demographic and attitudinal factors of adherence to quarantine guidelines during COVID-19: The Italian model. Frontiers in Psychology, 11, 559288. https://doi.org/10.3389/fpsyg.2020.559288.

Chen, Q., Liang, M., Li, Y., Guo, J., Fei, D., Wang, L., He, L., Sheng, C., Cai, Y., Li, X., Wang, J., \& Zhang, Z. (2020). Mental health care for medical staff in China during the COVID-19 outbreak. Lancet
Psychiatry, 7, e15-e16. https://doi.org/10.1016/S2215-0366(20) 30078-X.

Cheung, E. Y. (2015). An outbreak of fear, rumours and stigma: Psychosocial support for the Ebola virus disease outbreak in West Africa. Intervention, 13, 70-76.

Cohen, S., \& Wills, T. A. (1985). Stress, social support, and the buffering hypothesis. Psychological Bulletin, 98, 310-357. https://doi.org/10. 1037/0033-2909.98.2.310.

Cohen, S., Gottlieb, B. H., \& Underwood, L. G. (2000). Social relationships and health. In S. Cohen, B. H. Gottlieb, \& L. G. Underwood (Eds.), Social support measurement and intervention: A guide for health and social scientists (pp. 3-25). Oxford: Oxford University Press.

Cornine, A. (2020). Reducing nursing student anxiety in the clinical setting: An integrative review. Nursing Education Perspectives, 41(4), 229-234. https://doi.org/10.1097/01.NEP.0000000000000633.

Cornwell, B., \& Laumann, E. O. (2015). The health benefits of network growth: New evidence from a national survey of older adults. Social Science \& Medicine, 125, 94-106. https://doi.org/10.1016/j. socscimed.2013.09.011.

Dağll, A., \& Baysal, N. (2016). Yaşam Doyumu Ölçeği’nin Türkçe’ye uyarlanması: Geçerlik ve güvenirlik çalıșması [adaptation of the satisfaction with life scale into Turkish: The study of validity and reliability]. Elektronik Sosyal Bilimler Dergisi, 15, 1250-1262.

Di Giuseppe, M., Gemignani, A., \& Conversano, C. (2020). Psychological resources against the traumatic experience of COVID-19. Clinical Neuropsychiatry, 17, 85-87. https://doi.org/ $10.36131 / \mathrm{CN} 20200210$

Diener, E., Emmons, R. A., Larsen, R. J., \& Griffin, S. (1985). The satisfaction with life scale. Journal of Personality Assessment, 49, 71-75. https://doi.org/10.1207/s15327752jpa4901_13.

Duncan, L. A., Schaller, M., \& Park, J. H. (2009). Perceived vulnerability to disease: Development and validation of a 15-item self-report instrument. Personality and Individual Differences, 47, 541-546. https://doi.org/10.1016/j.paid.2009.05.001.

Eker, D., Arkar, H., \& Yaldız, H. (2001). Cok Boyutlu Algılanan Sosyal Destek Ölçeği'nin gözden geçirilmiș formunun faktör yapısı, geçerlik ve güvenirliği [Factorial structure, validity, and reliability of revised form of the Multidimensional Scale of Perceived Social Support]. Turk Psikiyatri Dergisi, 12, 17-25.

Ferreira, V. M., \& Sherman, A. M. (2007). The relationship of optimism, pain and social support to well-being in older adults with osteoarthritis. Aging and Mental Health, 11(1), 89-98.

Forshaw, M. (2002). Essential health psychology. Arnold.

Haktanır, A., Lenz, A. S., Can, N., \& Watson, J. C. (2016). Development and evaluation of Turkish language versions of three positive psychology assessments. International Journal for the Advancement of Counselling, 38, 286-297. https://doi.org/10.1007/s10447-0169272-9.

Haktanır, A., Seki, T., \& Dilmac, B. (2020). Adaptation and evaluation of Turkish version of the fear of COVID-19 scale. Death Studies, 1-9. https://doi.org/10.1080/07481187.2020.1773026.

Hall, R. C., Hall, R. C., \& Chapman, M. J. (2008). The 1995 Kikwit Ebola outbreak: Lessons hospitals and physicians can apply to future viral epidemics. General Hospital Psychiatry, 30(5), 446-452.

Harper, C, A, Satchell, L, P, Fido, D., \& Latzman, R, D. (2020). Functional predicts public health compliance in the COVID-19 pandemic. International Journal of Mental Health and Addiction, 1-14. https://doi.org/10.1007/s11469-020-00281-5.

Huang, Y., \& Zhao, N. (2020). Generalized anxiety disorder, depressive symptoms and sleep quality during COVID-19 outbreak in China: A web-based cross-sectional survey. Psychiatry Research, 112954. https://doi.org/10.1016/j.psychres.2020.112954.

Huelsnitz, C. O., Rothman, A. J., \& Simpson, J. A. (2018). Intimate relations, subjective well-being, and health behavior: Insight from 
a dyadic perspective. In J. E. Maddux (Ed.), Subjective well-being and life satisfaction (pp. 77-102). Routledge.

International Federation of Red Cross and Red Crescent Societies (IFRC). (2020). Mental health and psychosocial support for staff, volunteers and communities in an outbreak of novel coronavirus. https:// pscentre.org/wp-content/uploads/2020/02/MHPSS-in-nCoV-2020 ENG-1.pdf (accessed 5 May 2020).

Khoury, B., Sharma, M., Rush, S. E., \& Fournier, C. (2015). Mindfulness-based stress reduction for healthy individuals: A meta-analysis. Journal of Psychosomatic Research, 78, 519-528. https://doi.org/10.1016/j.jpsychores.2015.03.009.

Killgore, W. D. S., Taylor, E. C., Cloonan, S. A., \& Dailey, N. S. (2020). Psychological resilience during the COVID-19 lockdown. Psychiatry Research, 291, 1-2. https://doi.org/10.1016/j.psychres. 2020.113216

Kline, R. B. (2011). Principles and practices of structural equation modeling. Guilford Press.

Kuipers, S. (2020). Editorial: Sanity and resilience in times of Corona. Risks, Hazards and Crisis in Public Policy, 11(2), 110-115. https:// doi.org/10.1002/rhc3.12194.

Lee, S. A., \& Crunk, E. A. (2020). Fear and psychopathology during the COVID-19 crisis: Neuroticism, hypochondriasis, reassurance-seeking, and coronaphobia as fear factors. Omega-Journal of Death and Dying, 30222820949350, 003022282094935. https://doi.org/10. $1177 / 0030222820949350$

Li, Y., Sun, W., Sun, X., Sun, J., Yang, D., Jia, B., \& Yuan, B. (2020). Effects of mindfulness meditation on anxiety, depression, stress, and mindfulness in nursing students: A meta-analysis and trial sequential analysis of randomized controlled trials. Frontiers of Nursing, 7, 59-69. https://doi.org/10.2478/fon-2020-0001.

Liu, C. H., Zhang, E., Wong, G. T. F., Hyun, S. H., \& Hahm, H. C. (2020). Factors associated with depression, anxiety, and PTSD symptomatology during the COVID-19 pandemic: Clinical implications for U.S. young adult mental health. Psychiatry Research, 290, 1-7. https://doi.org/10.1016/j.psychres.2020.113172.

Lovibond, P. F., \& Lovibond, S. H. (1995). The structure of negative emotional states: Comparison of the depression anxiety stress scales (DASS) with the Beck depression and anxiety inventories. Behaviour Research and Therapy, 33, 335-343. https://doi.org/10. 1016/0005-7967(94)00075-U.

Mak, I. W. C., Chu, C. M., Pan, P. C., Yiu, M. G. C., \& Chan, V. L. (2009). Long-term psychiatric morbidities among SARS survivors. General Hospital Psychiatry, 31, 318-326. https://doi.org/10.1016/ j.genhosppsych.2009.03.001.

Maunder, R., Hunter, J., Vincent, L., Bennett, J., Peladeau, N., Leszcz, M., Sadavoy, J., Verhaeghe, L. M., Steinberg, R., \& Mazzulli, T. (2003). The immediate psychological and occupational impact of the 2003 SARS outbreak in a teaching hospital. CMAJ: Canadian Medical Association Journal, 168(10), 1245-1251.

Mazza, C., Ricci, E., Biondi, S., Colasanti, M., Ferracuti, S., Napoli, C., \& Roma, P. (2020). A nationwide survey of psychological distress among Italian people during the COVID-19 pandemic: Immediate psychological responses and associated factors. International Journal of Environmental Research and Public Health, 17, 3165. https://doi.org/10.3390/ijerph17093165.

Mei, S. L., Yu, J. X., He, B. W., \& Li, J. Y. (2011). Psychological investigation of university students in a university in Jilin province. Medicine and Society, 24, 84-86.

Mertens, G., Gerritsen, L., Duijndam, S., Salemink, E., \& Engelhard, I. M. (2020). Fear of the coronavirus (COVID-19): Predictors in an online study conducted in March 2020. Journal of Anxiety Disorders, 74, 102258. https://doi.org/10.1016/j.janxdis.2020. 102258.

Moghanibashi-Mansourieh, A. (2020). Assessing the anxiety level of Iranian general population during COVID-19 outbreak. Asian
Journal of Psychiatry, 102076, 102076. https://doi.org/10.1016/j. ajp.2020.102076.

Mucci, F., Mucci, N., \& Diolaiuti, F. (2020). Lockdown and isolation: Psychological aspects of COVID-19 pandemic in the general population. Clinical Neuropsychiatry: Journal of Treatment Evaluation, 17, 63-64. https://doi.org/10.36131/CN20200205.

Muthén, L. K., \& Muthén, B. O. (1998-2017). Mplus user's guide. (8th ed.). Muthén \& Muthén.

Özyeșil, Z., Arslan, C., Kesici, Ş., \& Deniz, M. E. (2011). Bilinçli Farkındalık Ölçeği’nin Türkçeye uyarlama çalıșması [Adaptation of the Mindful Attention Awareness Scale into Turkish]. Eğitim ve Bilim, 36, 224-235.

Patton, M. Q. (2001). Qualitative research \& evaluation methods, (3rd ed.). Sage Publications.

Polizzi, C., Lynn, S. J., \& Perry, A. (2020). Stress and coping in the time of COVID-19: Pathways to resilience and recovery. Clinical Neuropsychiatry, 17, 59-62. https://doi.org/10.36131/ CN20200204.

Rief, W., Hiller, W., \& Margraf, J. (1998). Cognitive aspects of hypochondriasis and somatization syndrome. Journal of Abnormal Psychology, 107, 587-595. https://doi.org/10.1037//0021-843x. 107.4.587.

Sarafino, E. P., \& Smith, T. W. (2011). Health psychology: Biopsychosocial interactions, (7th ed.). John Wiley \& Sons.

Sarıçam, H. (2018). The psychometric properties of Turkish version of depression anxiety stress Scale-21 (DASS-21) in health control and clinical samples. Journal of Cognitive-Behavioral Psychotherapy and Research, 7, 19-30. https://doi.org/10.5455/JCBPR.274847.

Satıc1, B., Gocet-Tekin, E., Deniz, M, E., \& Satıc1, S, A. (2020). Adaptation of the fear of COVID-19 scale: Its association with psychological distress and life satisfaction in Turkey. International Journal of Mental Health and Addiction, https://doi.org/10.1007/ s11469-020-00294-0.

Schimmenti, A., Billieux, J., \& Starcevic, V. (2020). The four horsemen of fear: An integrated model of understanding fear experiences during the COVID-19 pandemic. Clinical Neuropsychiatry, 17(2), 4145. https://doi.org/10.36131/CN20200202.

Smith, B. W., Dalen, J., Wiggins, K., Tooley, E., Christopher, P., \& Bernard, J. (2008). The brief resilience scale: Assessing the ability to bounce back. International Journal of Behavioral Medicine, 15, 194-200. https://doi.org/10.1080/10705500802222972.

Su, T. P., Lien, T. C., Yang, C. Y., Su, Y. L., Wang, J. H., Tsai, S. L., \& Yin, J. C. (2007). Prevalence of psychiatric morbidity and psychological adaptation of the nurses in a structured SARS caring unit during outbreak: A prospective and periodic assessment study in Taiwan. Journal of Psychiatric Research, 41(1-2), 119-130. https://doi.org/10.1016/j.jpsychires.2005.12.006.

Tabachnick, B. G., \& Fidell, L. S. (2007). Using multivariate statistics. Pearson Education.

Taylor, S. (2019). The psychology of pandemics: Preparing for the next global outbreak of infectious disease. Newcastle upon Tyne: Cambridge Scholars Publishing.

Taylor, S., \& Asmundson, G. J. G. (2004). Treating health anxiety: A cognitive-behavioral approach. Guilford Press.

Taylor, S., Landry, C., Paluszek, M., Fergus, T. A., McKay, D., \& Asmundson, G. J. (2020). Development and initial validation of the COVID stress scales. Journal of Anxiety Disorders, 102232, 102232. https://doi.org/10.1016/j.janxdis.2020.102232.

Trzebiński, J., Cabański, M., \& Czarnecka, Z. (2020). Reaction to the COVID-19 pandemic: The influence of meaning in life, life satisfaction, and assumptions on world orderliness and positivity. Journal of Loss and Trauma, 25(6-7), 544-557. https://doi.org/10. 1080/15325024.2020.1765098.

Vinkers, C. H., van Amelsvoort, T., Bisson, J. I., Branchi, I., Cryan, J. F., Domschke, K., Howes, O. D., Manchia, M., Pinto, L., de Quervain, D., Schmidt, M. V., der Wee, v., \& Nic, J. A. (2020). Stress 
resilience during the coronavirus pandemic. European Neuropsychopharmacology, 35, 12-16.

Wang, J., \& Wang, X. (2020). Structural equation modeling: Applications using Mplus. (2nd ed.). John Wiley \& Sons.

Wang, C., \& Zhao, H. (2020). The impact of COVID-19 on anxiety in Chinese university students. Frontiers in Psychology, 11, 1168. https://doi.org/10.3389/fpsyg.2020.01168.

Wang, C., Pan, R., Wan, X., Tan, Y., Xu, L., Ho, C. S., \& Ho, R. C. (2020). Immediate psychological responses and associated factors during the initial stage of the 2019 coronavirus disease (COVID-19) epidemic among the general population in China. International Journal of Environmental Research and Public Health, 17, 11-25. https://doi.org/10.3390/ijerph17051729.

World Health Organization, 2020. Mental health and psychosocial considerations during the COVID-19 outbreak.https://www.who.int/ docs/default-source/coronaviruse/mental-healthconsiderations. pdf? sfvrsn=6d3578af_8 (accessed 15 April 2020).

Xiang, Y. T., Yang, Y., Li, W., Zhang, L., Zhang, Q., Cheung, T., \& Ng, C. H. (2020). Timely mental health care for the 2019 novel coronavirus outbreak is urgently needed. Lancet Psychiatry, 7, 228-229. https://doi.org/10.1016/S2215-0366(20)30046-8.

Zimet, G. D., Powell, S. S., Farley, G. K., Werkman, S., \& Berkoff, K. A. (1990). Psychometric characteristics of the multidimensional scale of perceived social support. Journal of Personality Assessment, 55, 610-617.

Publisher's Note Springer Nature remains neutral with regard to jurisdictional claims in published maps and institutional affiliations. 